\title{
O EFEITO DO PROJETO SOBRE A PRODUÇÃO
}

\author{
BERENICE MARTINS TORALLES CARBONARI ${ }^{a}$
}

CARBONARI, B.M.T. O efeito do projeto sobre a produção. Semina, v. 12, n. 4, p.224-229, dez. 1991.

\section{RESUMO}

O presente trabalho tem por objetivo enfocar a importância do projeto sobre o processo de produção. Tal importância diz respeito à influência direta do projeto sobre a gerência de produção, pois, mediante delimitações feitas no projeto decisões serão tomadas em termos de prazos, tamanho, seqüência de trabalho, equipamentos e distribuição de mão-de-obra. Também é enfocado o aspecto da influência do projeto sobre a produção quando há variação na tecnologia adotada, como por exemplo: construção tradicional, blocos de concreto e cerâmica e formas túneis. Na fase conclusiva êfeito um "checklist" de algumas interferências que podem ocorrer se não houver o devido cuidado tanto na fase de elaboração como execução do projeto gerando com isto descontinuidade no processo de produção.

PALAVRAS CHAVES :Projeto, Racionalização, "Check-list", Processo de Produção.

\section{1 - INTRODUÇÃO}

O projeto tem grande Influência no processo de produção, visto que decide o fim e o desempenho desse processo. Resulta daí uma direta ligação entre o processo de produção e o projeto.

É muito importante que o projeto seja elaborado minuciosamente, levando em consideração fatores tanto internos como externos a ele, o que vai além de uma simples lista de atividades ("check-list") pois que abrange também reflexões sobre todos os fatores intervenientes no processo. Em um projeto, qualquer detalhe desnecessário, desconsiderado ou mal projetado, poderá acarretar erros no processo de produção e, inclusive, conforme a gravidade, inviabilizar o todo pretendido.

Um projeto que empregue uma nova tecnologia deve ser cuidadosamente estudado, para que, na fase de execução, não ocorram erros decorrentes da falta de cuidado ao projetar.

Tanto em obras tradicionais, onde existe uma certa flexibilidade no processo de produção, pois, não há uma peocupação com a seqüência rígida das operações, sendo possível improvisar, como em obras racionalizadas, onde existe uma preocupação com a exatidão e com a continuidade, o projeto é, sempre, como se disse acima, a base do processo de produção.

Evidencia-se, portanto, sua influência direta sobre gerência da produção, pois é mediante o projeto que serão tomadas decisões em termos de prazo, tamanho, seqüência de trabalho, equipamentos e distribuição de mão-de-obra.

Por isso, o projeto deve permitir uma certa flexibilidade, de modo que, se for necessário, reformulações sejam feitas, mantendo-se a estrutura inicial do projeto.

O projeta auxiliará na continuidade ou não do processo de produção. O que se objetiva com a continuidade é que uma operação, para começar, tenha a sua precedente concluída, ou seja, que não ocorram interferências entre as ações das equipes as quais não devem retornar a um serviço após terem iniciado outro.

Se for levado em conta o processo tradicional de construção, verifica-se que a descontinuidade começa a aparecer da metade da obra para fernte, onde há um grande número de interferências e um conseqüente aumento dos homens-hora exigidos, principalmente nos serviços de instalações elétricas, hidráulicas e acabamentos. A figura A.2.1 abaixo mostra que, no início, os serviços encontram-se bem delineados, ocorrendo depois uma certa confusão no processo, devido a uma série de interferências.

Isto se deve ao fato de que, no início da obra, os serviços estão bem discriminados, com equipes bem definidas e da metade da obra para frente esta definição já não é mais encontrada. Por exemplo, para que se inicie a alvenaria necessariamente, a subestrutura tem que estar acabada. 0 mesmo não ocorre com os serviços de instalações elétricas e hidráulicas onde se verifica, principalmente em obras tradicionais, várias idas e vindas até a complementação des- 


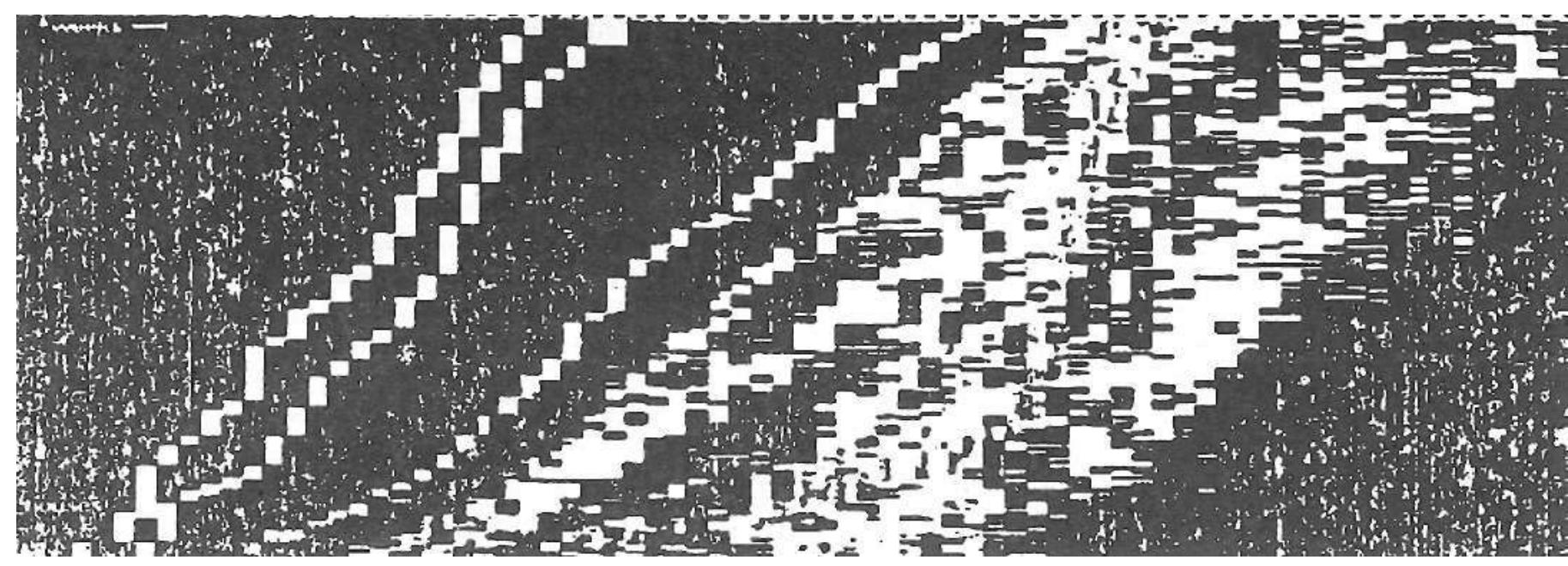

FIGURA A.2.1

tes serviços, caracterizando-se assim uma descontinuidade no processo de produção. Este problema é também verificado nos serviços de acabamentos onde uma série de retornos tem que ser efetuados até a conclusão deste serviço.

Para minimizar o problema da descontinuidade, a solução está na racionalização destes serviços, de maneira que estes venham a se tornar mais contínuos e com isto se possa diminuir o número de homens-hora exigidos.

$\mathrm{Na}$ figuras apresentadas a seguir, procura-se mostrar os serviços de instalações hidráulicas empregando:

- tecnologia tradicional

- com blocos

- com formas

A figura A.2.2 mostra a planta hidráulica de uma residência unifamiliar,

Se o projeto acima for executado com tecnologia tradicional o primeiro passo é o demonstrado na figura a seguir (figura A.2.3).

Primeiramente, ievanta-se a alvenaria e a seguir fazem-se os rasgos onde irá passar a canalização. Verificase assim, que a conclusão do serviço exige várias idas e vindas dos executores. Faz-se o rasgo, o instalador coloca a canalização* e, em seguida, o pedreiro retorna para fazer o fechamento do rasgo. Mais tarde, o instalador retoma para instalar os aparelhos.

Constata-se que o serviço é descontínuo e que, por isso, exige um maior número de homens-hora para sua complementação.

Uma alternativa que evitaria a operação rasgo na alvenaria e conseqüente fechamento do rasgo, seria a utilização de uma parede dupla como mostra a figura A.2.4.

Mo caso de empregar-se tecnologia racionalizada, blocos de concreto ou cerâmica ter-se-ia a eliminação do rasgo e do conseqüente fechamento. A instalação ocorreria em conjunto com a elevação da parede, ou através de "kits" hidráulicos, previamente preparados no canteiro da obra (figura A.2,5).

Em projetos racionalizados tem-se um maior trabalho de prancheta. No caso acima, no projeto deverá estar prevista a colocação de canaletas invertidas para os ramais horizontais, procurando deixar os verticais coincidirem com Semina, Ci. Exatas/Tecnol., v.12, n.4, p.224-229, dez. 1991 os furos dos blocos, cujos cortes serão igualmente previstos no projeto.

Os pontos de saída para os aparelhos devem ser planejados de forma que, no caso de colocação de azulejos, o corte dos mesmos seja facilitado.

No caso de tecnologia de formas, são colocadas nestas, em posições previamente determinadas no projeto, negativos, onde, apôs a concretagem e retirada dos negativos será feita a instalação hidráulica (figura A.2.6).

Neste caso, após a montagem da canalização, deverá haver o fechamento do rasgo.

Nas instalações elétricas ocorre, mais ou menos, a mesma coisa.

Se for considerado o processo tradicional da construção, primeiramente levanta-se a alvenaria, faz-se o rasgo coloca-se o conduto elétrico e posteriormente procede-se ao fechamento do rasgo.

A figura A.2.7 mostra o croqui de uma instalação elétrica com tecnologia de blocos.

Tal como ocorre na instalação hidráulica, ao ser planejado o projeto elétrico, os cuidados com os detalhes são importantes para que não ocorram erros no momento da execução.

Se a tecnologia utilizada for a de formas, o conduto elétrico pode ser previamente fixado a estas, por meio de grampos. Em seguida, a forma pode ser concretada, tomando-se o cuidado de não deixar o concreto penetrar no conduto.

Nas instalações elétricas, como nas instalações hidráulicas, podem ser deixados negativos para que, posteriormente à concretagem e desforma, sejam colocados os condutos elétricos.

Nota-se que, em termos de instalações elétricas e hidráulicas a continuidade do processo se deve muito ao tipo de tecnologia. Em termos dos serviços de acabamento, para se evitar a descontinuidade, prega-se muito a eliminação do reboco, mas, para que tal procedimento se torne eficaz, é necessário que esta eliminação seja total.

Até aqui foi considerado o problema da descontinuidade advinda do tipo de tecnologia adotada. A seguir, 
será feita uma listagem de algumas interferências que podem ocorrer se não forem considerados certos detalhes na elaboração e execução do projeto o que resultará em descontinuidade no processo de produção.

- Andaimes, reflita-se sempre com antecipação sobre a forma pela qual serão colocados: se presos nas platibandas, dificultam o acabamento; se fixados nas paredes, exigem a prévia perfuração dessas.

- Vigas e colunas, estabeleça-se seqüência adequada para as operações de concretagem, uma vez que, para remoção, a prioridade é para os pilares.

- Tijolos, quando portantes, cuide-se para que, sua elevação não seja interrompida pela execução da laje; no caso de tijolos à vista ou blocos sem reboco, dediquese atenção especial à primeira fiada, cujo nível deve ser perfeito.

- Marcos e esquadrias, lembre-se que o estabelecimento de medidas e a própria montagem das esquadrias exigem acabamento prévio das estruturas, supondo sempre o enchimento de contramarcos, pelas irregularidades dos pilares de concreto de que resultam vãos igualmente irregulares. Além disso, verifique-se, com cuidado, o acabamento junto ao piso, e arremates externos e internos.

- Azulejos, cuide-se para que o trânsito interno não acarrete problemas de quebras, bem como para que resul- tem perfeitos os arremates nos limites com instalações hidráulicas e esquadrias. Além disso providencie-se para que a primeira fiada de azulejo comece no nível certo do piso, para que coincidam azulejos e piso.

- Pisos, quando quadriculados verifique-se alinhamento em todo um andar ou em peças muito amplas. Deve-se também tomar cuidados para que os encanamentos não acarretem furos ou desníveis nos pisos.

- Degraus e espelhos, em escadas, nivelamento de pisos, considerem-se sempre que ocorrem diferenças de andar para andar, motivo por que os espelhos só podem ser feitos sob medida, após o nivelamento entre os dois andares.

- Soleira dos elevadores, tenha-se em vista a máxima correção no estabelecimento de níveis.

- Caixas e eletrodutos, devem ser resguardados de entupimento durante a concretagem.

- Canos, sejam previstas formas de resolver dificuldades como:

a) de enfiação, no caso de canos com muitas curvas;

b) canos na laje de rebaixo e forro de gesso;

c) caimento: seja previsto o espaço para tal e tenhase em vista que, os canos muitas vezes se cruzam no espaço.

É muito importante a análise detalhada do projeto para que transcorra sem problemas o processo de produção.

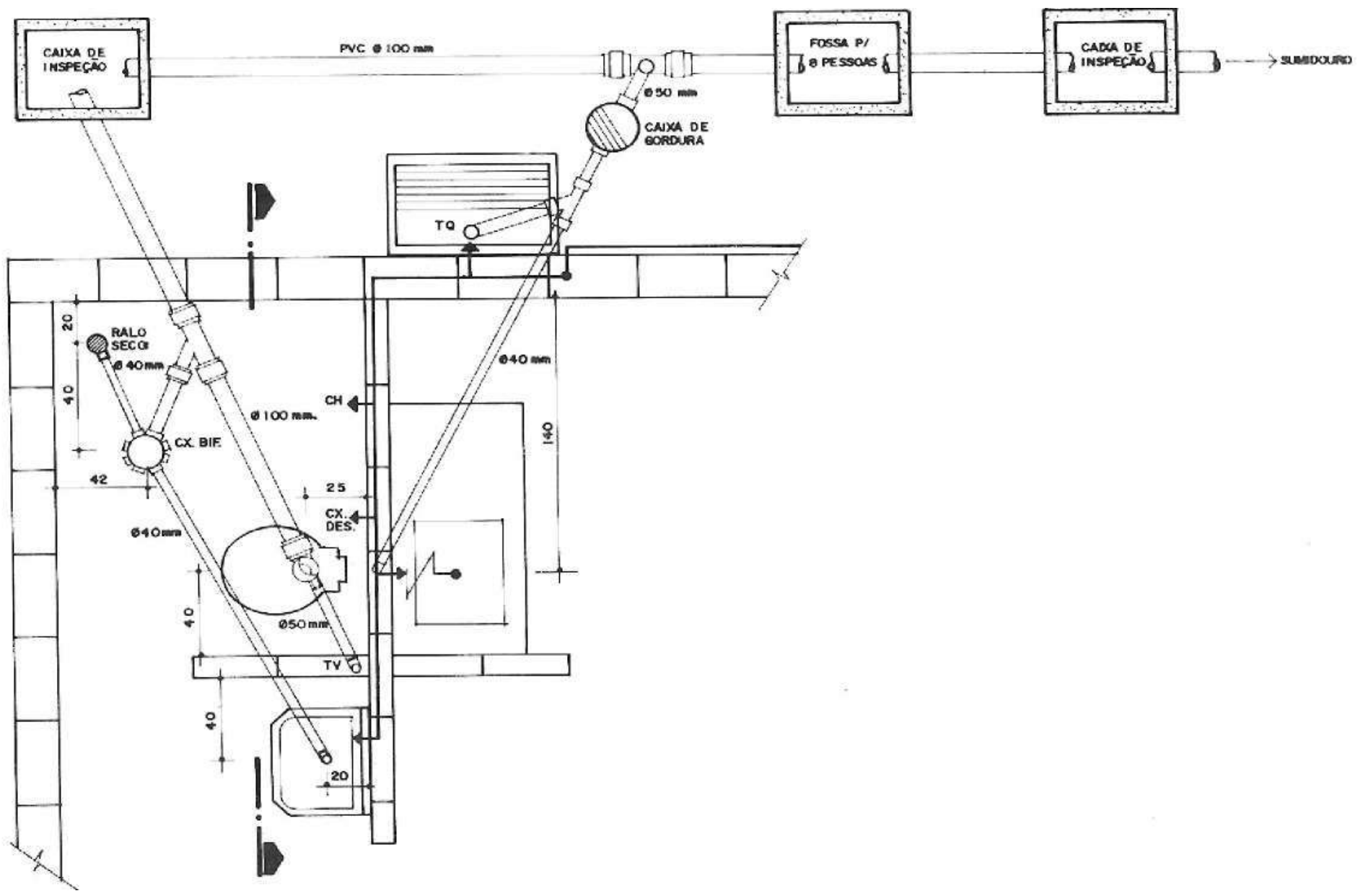

FIGURA A.2.2

Semina, Ci. Exatas/Tecnol., v.I2, n.4, p.224-229, dez. 1991 


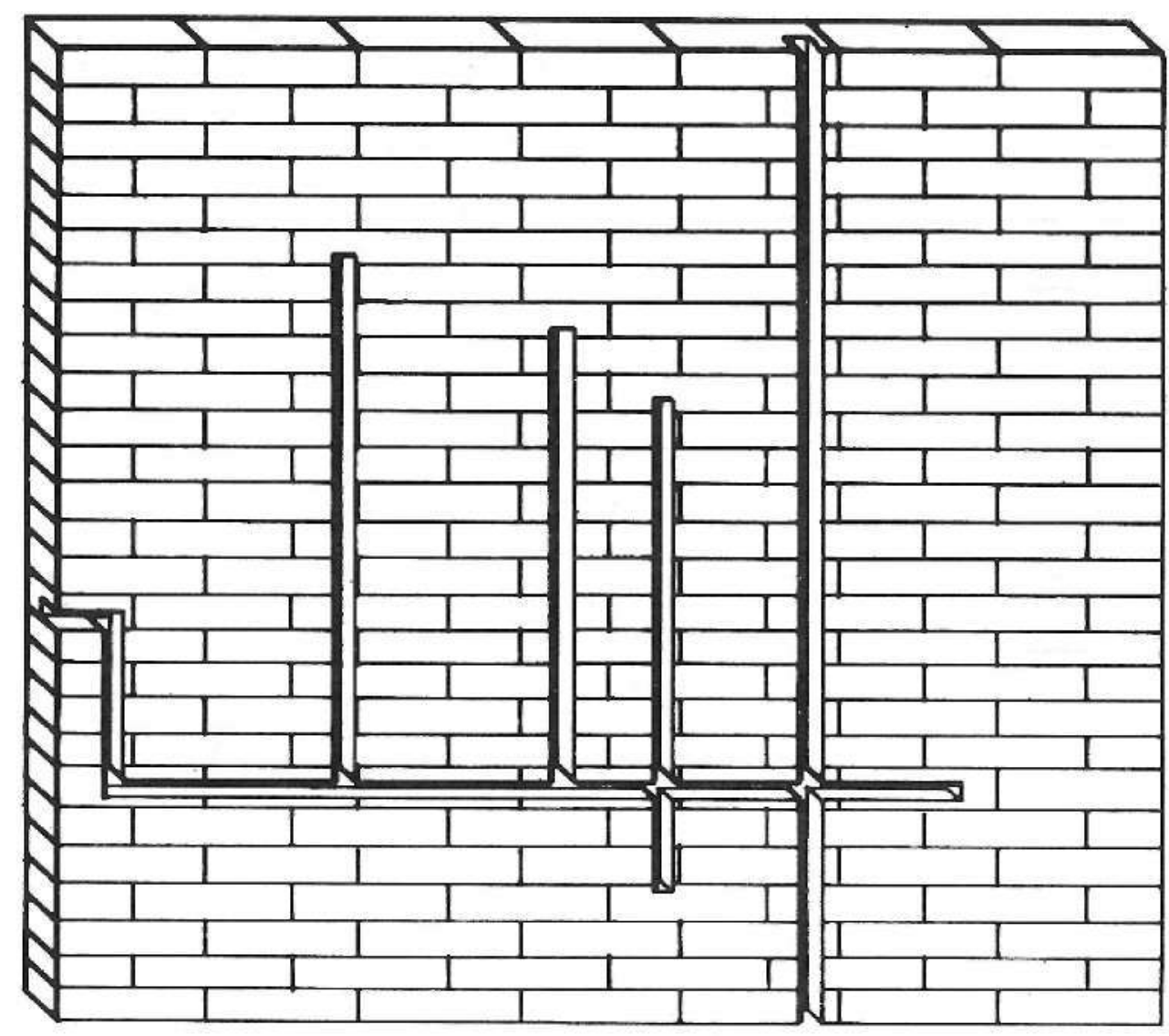

FIGURA A.2.3

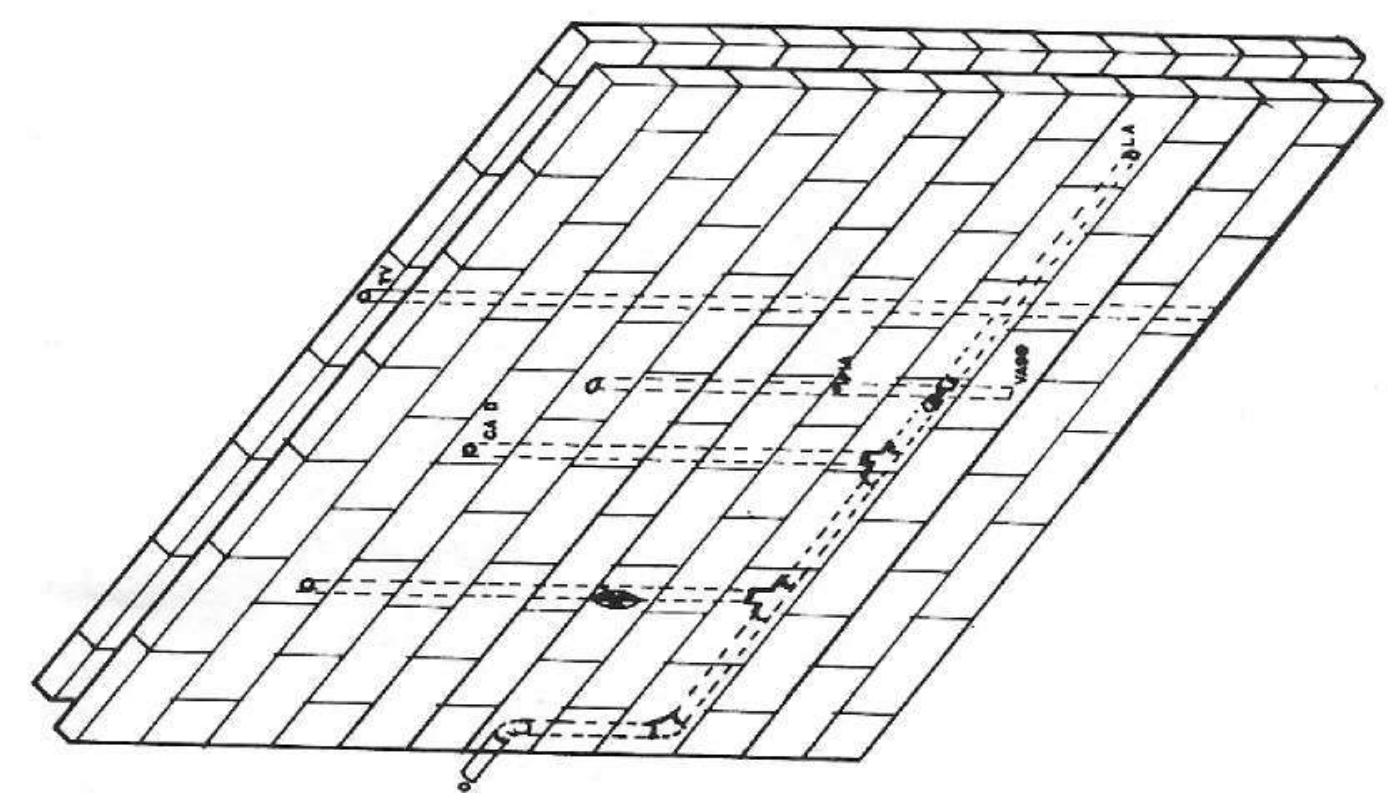

FIGURA A.2.4 


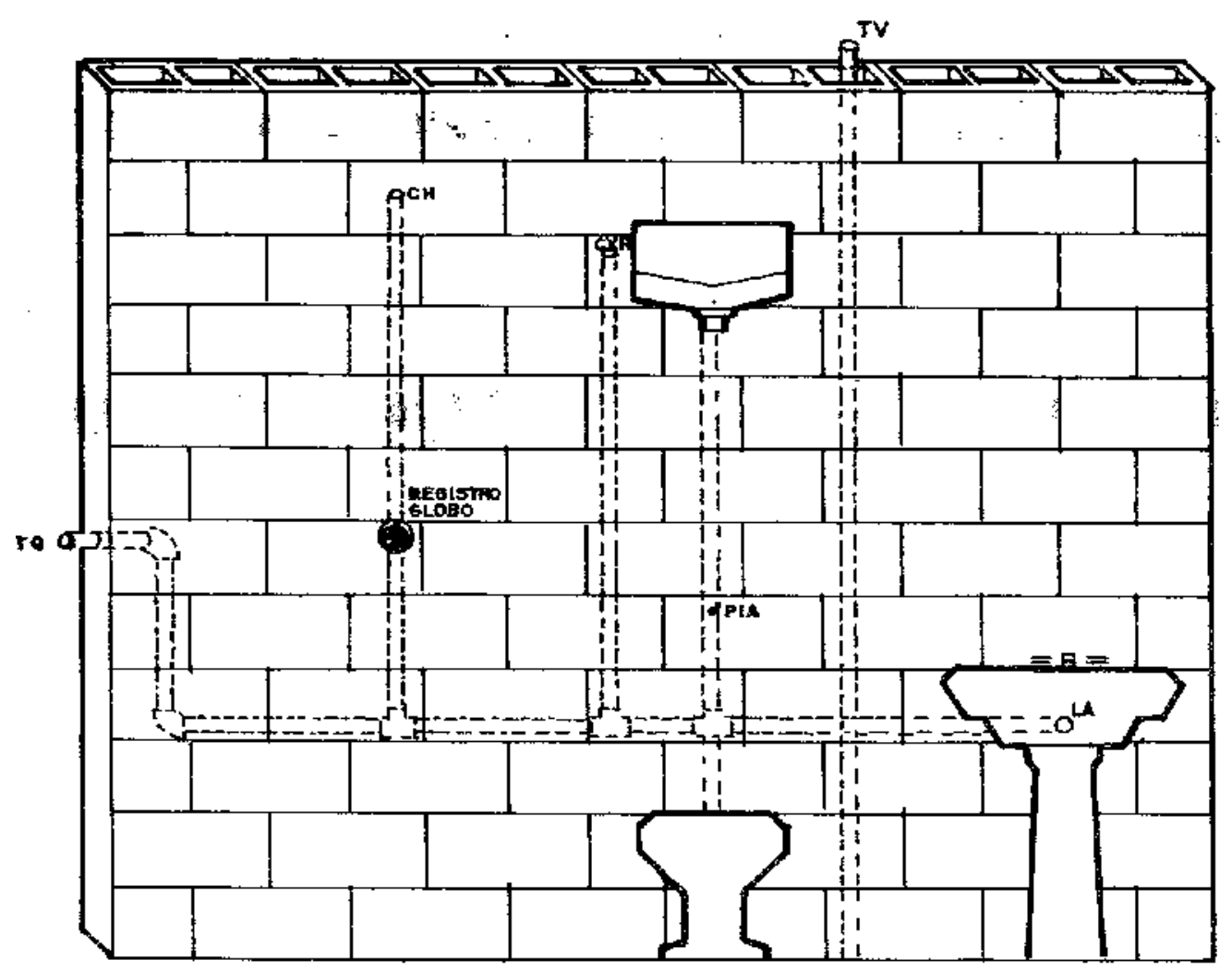

FIGURA A.2.5

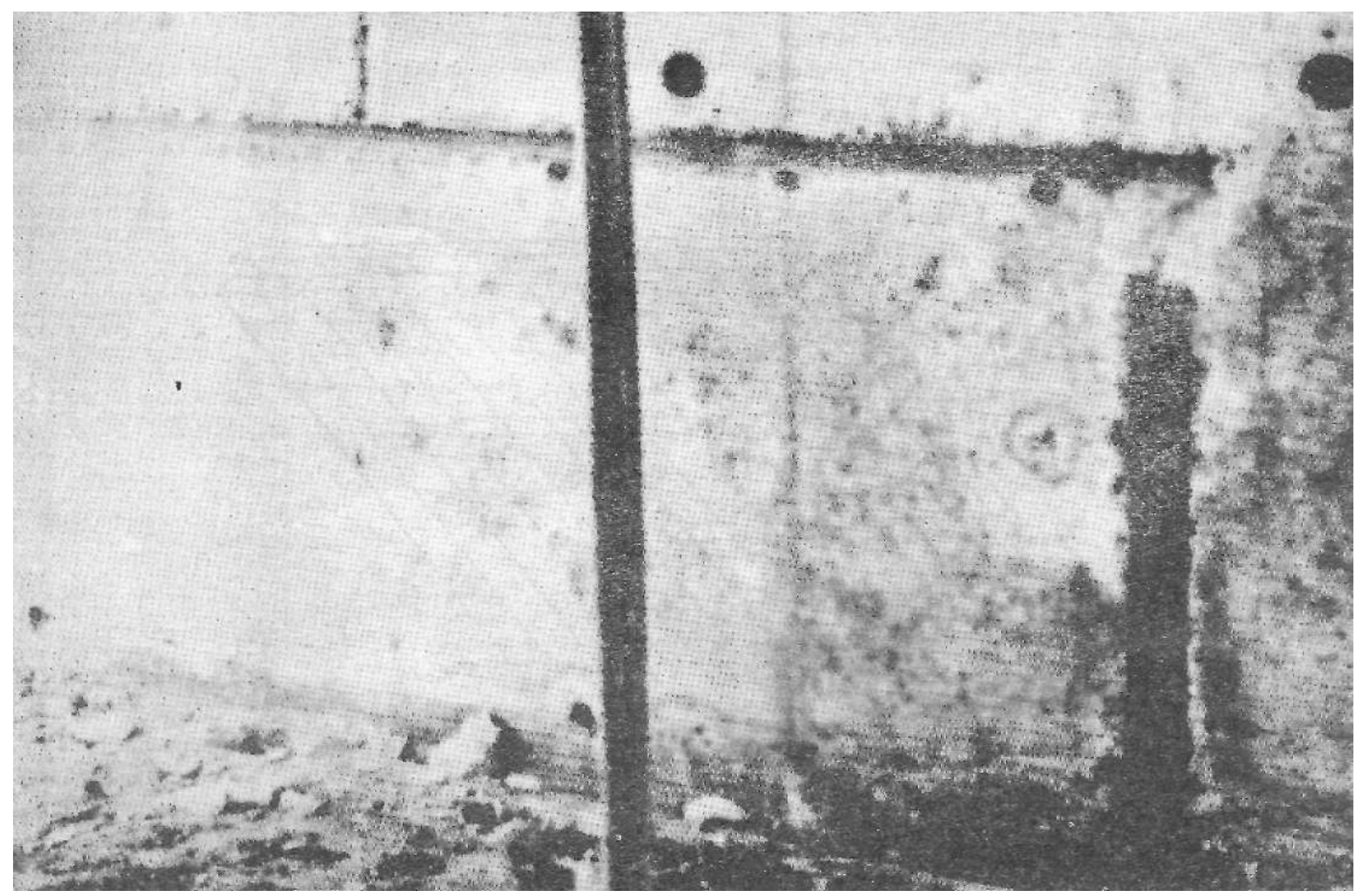

FIGURA A.2.6

Semina, Ci. Exatas/Tecnol., v.12, n.4, p.224-229, dez. 1991 


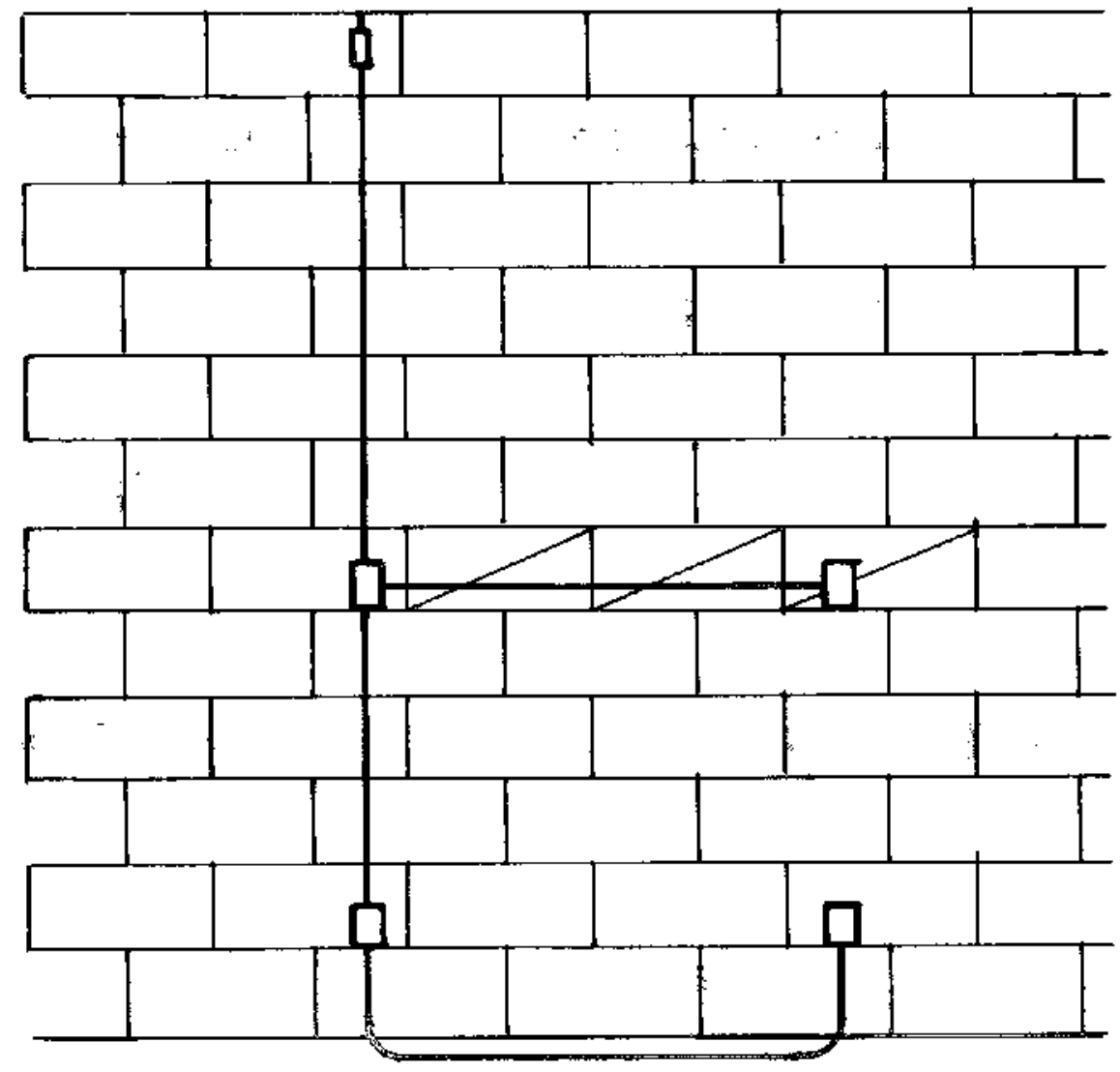

FIGURA A.2.7

CARBONARI, B.M.T. The effect of the Project on the production process. Semina, v. 12, n. 4, p.224-229, Dec. 1991.

\section{ABSTRACT}

The objective of the present research is to focus on the importance of a project on the production process. Such an importance is concerned with the direct influence of the project on the production management, because, through delimitations in the project, decisions can be taken in terms of deadline, size, sequence of work, equipments and distribution of workmanship. We also focussed on the aspect of the project influence on the product whenever we found variation in the adopted technology, such as traditional construction, concrete and ceramic blocs and tunnel-form. A check-list was done during the conclusions stage related to some interferences which may occur whenever there is not the right care in the elaboration and execution stages, generating, thus, discontinuity in the production process.

KEY-WORDS: Project, Rationalization, Check-list and Production Process.

\section{REFERÊNCIAS BIBLIOGRÁFICAS}

1 - BURGESS, R.A. \& MORRIS, P.W.G. Organisational relationship between design and construction in building. In: CONGRESS OF CIB, Budapest, 1974. p. 222-7. Anais

2 - EDEN, J.F. The assembly process in house buitding. Building, London, 223: 98-104, June, 1972.

\author{
$\therefore \quad$ Project. Building, London, 223 (6761): 111-24, \\ Oct. 1972. \\ 4 - MORRIS, P.W.G. Influences of design upon production. \\ Building technology and Management, London, p. 6-10, \\ Oct. 1971.
}

